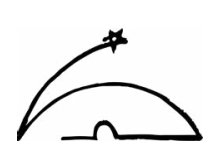

\title{
Max Schmidt en el Mato Grosso ${ }^{1}$
}

Federico Bossert \& Diego Villar ${ }^{2}$

\begin{abstract}
Between 1899 and 1929, Max Schmidt worked for the Berlin Ethnological Museum and undertook three expeditions to the Mato Grosso in order to continue the investigations of his mentor Karl von der Steinen. Between 1900 and 1901 he explored the upper Xingu trying to reach Kamaiurá territory, meeting several Bacairí, Nahukuá and Aweti Indians, and also the Guato of the swamps of upper Paraguay. In 1910 he attended the International Congress of Americanists in Buenos Aires and seized the opportunity to study the Paresí. Between 1926 and 1928 he undertook a final voyage to the upper Xingu and visited the Bacairí, Kaiabi, Paresí, Iranches and Umotinas. In these trips Schmidt took dozens of pictures that document indigenous life and the first interethnic contacts. The paper presents the ethnographic context of these pictures discussing the incidents of each journey, reported in detailed travelogues; the exploration and conquest of the indigenous Mato Grosso by State agents and rubber barons; the ethnographic and methodological heritage of Adolf Bastian, Karl von der Steinen and the ongoing discussion in German ethnology, and Schmidt's own theoretical and museographical interests. Finally it discusses Schmidt's ethnographic fieldwork and the role photography played in it.
\end{abstract}

\section{La etnología alemana y el Mato Grosso}

El 19 de marzo de 1900, luego de pasar algunos meses en Cuiabá esperando el fin de la estación lluviosa escuchando los relatos de los colonos caucheros sobre la hostilidad de los indígenas xinguanos, el joven Max Schmidt iniciaba por fin su anhelada expedición al Mato Grosso, internándose en la selva en busca de las tierras bacairís sobre el río Curisevo. Marchaba al frente de una singular comitiva: un joven, un niño, tres burros y una mula. Poseía recursos materiales más bien limitados y un precario dominio del portugués, que sólo había comenzado a aprender en el barco que lo trajo desde Asunción. Como toda guía geográfica y lingüística, y como toda carta de presentación ante los indígenas, cargaba las obras de Karl von den Steinen.

Apenas unos meses antes de embarcarse en este extraño viaje a Sudamérica, Schmidt proseguía, siguiendo los pasos paternos, una carrera en leyes como funcionario en las cortes

$1 \quad$ Una versión en inglés del texto fue publicada en FISCHER, Manuela; KRAUS, Michael (eds.), Exploring the Archive. Historical Photography from Latin America. The Collection of the Ethnologisches Museum Berlin. Köln: Böhlau Verlag, 2015. p. 280-298. 
provinciales de Kiel y Blankanese, preparando una tesis sobre la razón jurídica en el Derecho Romano. Por razones que desconocemos -pero que cierto tono romántico en alguna de sus primeras páginas sugiere- solicitó en 1899 una licencia, se trasladó a Berlín y se inscribió como voluntario en el Museo de Etnología de esa ciudad. Allí conocería a Steinen, su maestro en la todavía incipiente etnología -quien, a su vez, era uno de los principales discípulos del gran promotor de la etnología alemana en las últimas décadas del siglo XIX, Adolf Bastian, fundador de algunas de las instituciones donde Schmidt se formaría y trabajaría: el colosal Museo de Etnología y la Berliner Gesellschaft für Anthropologie, Ethnologie und Urgeschichte (GINGRICH, 2005: 84). En efecto, son varias las posiciones de Bastian -de raigambre humboldtiana- que podemos identificar en las investigaciones etnográficas de Schmidt: la definición no esencialista de los Naturvölker, y su puesta en valor como objeto privilegiado del estudio etnológico (PENNY, 2002: 23; KRAUS, 2007: 142); la misión de "salvataje" de la etnografía ante el avance colonial y la expansión de la influencia cultural europea (BUNZL, 1996: 48; THIEME, 1993: 45); y, ante todo, la convicción de que el viaje, el trabajo de campo, la observación directa de las culturas, eran la única forma válida de obtener conocimientos etnológicos: sólo eran válidas las investigaciones estrictamente inductivas que basaran cada afirmación en evidencias empíricas confiables, y que por lo tanto prestaran atención a los más ínfimos detalles de la cultura estudiada (KRAUS, 2007: 148; PENNY, 2002: 19-20). Tras su muerte, cuando la escena antropológica germano-parlante fue conquistada por nuevas escuelas que proponían ambiciosos esquemas universales -los Kulturkreise de Fritz Graebner o bien el monoteísmo primitivo del Pater Wilhelm Schmidt-Schmidt iba a mantenerse, aún a costo de cierta postergación académica, fiel a este empirismo inductivo mucho más cauteloso, e incluso realizaría serias impugnaciones a las tesis difusionistas imperantes (GINGRICH, 2005: 91-92; KRAUS, 2007: 148). Steinen era la figura más prominente de un círculo de etnógrafos alemanes interesados en las selvas sudamericanas: en 1884 había realizado una hazaña inédita al descender el inexplorado río Xingu desde sus nacientes hasta la desembocadura en el Amazonas, y en 1887 regresaba a la región para concentrarse en sus sociedades indígenas, virtualmente desconocidas hasta ese entonces. Las obras que plasmaron los resultados de estos viajes -en particular Unter den Naturvöljern Zentral-Brasiliens- iban a revolucionar el debate etnológico de la época y a ofrecer un esquema de clasificación étnica y lingüística del área xinguana que, en líneas generales, sería suscrito por la etnología y la lingüística posteriores (SCHADEN, 1993: 112). Bajo su influencia toda una generación de etnólogos alemanes se interesó por esta región, y se multiplicaron las expediciones al Brasil: Paul Ehrenreich (en 1885 y 1887), Hermann Meyer (en 1896 y 1899), Theodor Koch-Grünberg (entre 1904 y 1905). El interés de Schmidt por el Mato Grosso sin dudas fue resultado directo de ese contexto académico. Pero, al mismo tiempo, la región poseía en sí misma ciertos atractivos insoslayables: por un lado, era en buena medida una terra incognita, apta para la exploración pionera -en la época, una meta inseparable de la etnología- y ofrecía la oportunidad de contactar a los 
auténticos Naturvölker; por el otro, presentaba una abigarrada aglomeración étnica, ideal para el estudio del contacto interétnico y los procesos de transformación recíproca entre las sociedades indígenas.

Si bien comenzaba repitiendo el periplo seguido por Steinen en 1887, el primer viaje de Schmidt fue singular en más de un sentido. En primer lugar, a diferencia de las típicas expediciones de la época, integradas por varios investigadores y una gruesa comitiva, Schmidt viajaba solo, en la cambiante compañía de guías indígenas. En segundo lugar, y fundamentalmente, la meta del viaje no era una mera exploración etnológica: diseñada por Steinen, su intención era realizar una investigación intensiva entre los kamaiurás, con quienes planeaba convivir por algunos meses - un proyecto bastante singular en una época en la cual los etnólogos no se demoraban en investigaciones localizadas. Cada uno de los viajes que a lo largo de las décadas realizaría a las zonas del alto Xingu y el alto Paraguay respondía a ese mismo patrón: una mezcla de elección metodológica e íntimo anhelo espiritual (BOSSERT; VILLAR, 2013: 2-53).

Sin embargo, a pesar de sus infatigables empeños, Schmidt nunca llegó a ver a los kamaiurás. El relato de este viaje al alto Xingu es una sucesión de accidentes, infortunios y pequeñas tragedias, narrados en Indianerstudien in Zentralbrasilien (SCHMIDTS, 1942b) con una rara mezcla de infatigable optimismo y meticulosidad científica. La figura de Schmidt que dibujan esas páginas tiene algo de quijotesca: delgado, altísimo, estoico, siempre filosófico, internándose en la selva en compañía de indígenas a los que apenas comprende con un atado de libros como toda guía.

\section{Viajes por la selva}

Cuarenta y cuatro días después de partir de Cuiabá, Schmidt llegaba por fin al río Curisevo, que junto con el Ronuro, el Batoví, el Kuluene y el Von den Steinen forman la región conocida como "alto Xingu". Allí estaban los bacairís, con quienes utilizó por primera vez las estrategias diplomáticas a las que recurriría incontables veces durante sus viajes: enseñar los viejos grabados de los libros de Steinen o entonar en su violín la canción Margarethe, Mädchen ohne Gleichen. En compañía de algunos bacairís comenzó a descender en canoa el Curisevo, compartiendo la vida indígena, comiendo con ellos, emulando su desnudez e incluso haciéndose tatuar sus diseños en el brazo: “Aquellos días en el seno de la naturaleza virgen, compartiendo la vida salvaje con sin preocuparme por los cuidados y las necesidades, están entre mis mejores recuerdos de ese viaje" (SCHMIDT, 1942b: 55). El escenario cambiaría pronto, al adentrarse en territorio de los nahukuás: a lo largo de varias paradas, en las que era sometido a trueques que no sabía rechazar, Schmidt comenzó a observar con desesperación que su carga de baratijas -traídas para retribuir objetos, comida y servicios- comenzaba a extinguirse rápidamente. Además, la relación con sus guías nahukuás comenzó a volverse tensa, sembrada de desconfianza, pequeños hurtos y vigilias nocturnas con las armas de fuego preparadas para la acción. Así llegó a territorio de los awetis, 
donde lo que debía ser apenas una breve parada en el camino hacia los kamaiurás se convertiría en la estación final de su viaje. Descriptas con humor sutil, las jornadas que Schmidt y su compañero André pasaron en esa aldea componen una de las páginas más memorables del libro. Los awetis los invitan a quedarse con ellos y se lanzan alegremente sobre los equipajes, ofreciéndose a cargarlos; Schmidt observa consternado que sus ya menguadas pertenencias se dispersan por la selva, y desaparecen. Al llegar a la aldea realiza el inventario: ya no le queda casi nada para intercambiar con los kamaiurás. En un solo golpe, sus planes se han frustrado. Incansable, decide adaptarse a las circunstancias y quedarse con los awetis. Pero los acontecimientos se precipitan: mientras los viajeros duermen, esa noche desaparecen sus últimas pertenencias. Por la mañana Schmidt intenta llegar a un acuerdo con el indolente jefe, desencadenando el apoteótico final:

\footnotetext{
"Nuestras circunstancias parecían haber mejorado. Entonces, dejando al cacique a cargo de nuestro equipaje por un rato, fuimos con André a bañarlos en un arroyo cercano. Al regresar encontramos al cacique rodeado por nativos, entre quienes distribuía los últimos objetos de nuestra bolsa de ropa. Todo lo que me quedaba era la camisa que estaba usando y unos pantalones harapientos. Hasta el último objeto: todo lo que había en la bolsa había desaparecido. Entonces declaré a André que a primera hora estaríamos regresando a los bacairís." (SCHMIDT, 1942b: 65).
}

Los viajeros pasan la noche en el interior de la choza vigilando sus armas y escuchando, sin poder siquiera presenciarlas, las danzas rituales que tienen lugar en la plaza. Y al día siguiente, en el camino hacia los botes, los indígenas desaparecen con las últimas pertenencias, incluyendo las colecciones etnográficas. El viaje posterior hacia las tierras bacairís es una huida sombría y silenciosa, evitando en lo posible el contacto con los indígenas como no sea para comprar algo de pescado que pagan con sus últimos botones y anillos. Ni siquiera la devolución de las colecciones por una canoa aweti logra atenuar la decepción -Schmidt de hecho supone que se trata de un pago para evitar la venganza: "No había encontrado lo que había venido a buscar: convivir con los hijos de la selva. El esfuerzo prodigioso requerido y la ansiedad constante me otorgaban escasos momentos de placer... y ahora me estaba yendo" (SCHMIDT, 1942b: 75). Así que transcurre sus últimos días entre los bacairís sin poder dedicarse a la etnografía, postrado en una hamaca, enfermo de malaria, atormentado por las noches por danzas y cantos rituales que parecen especialmente destinados a evitar su sueño, y durante el día por niños y mujeres que se sientan sobre su cuerpo y lo obligan a interpretar una y otra vez la canción Margarethe.

El epílogo de esta aventura, el regreso hacia Cuiabá, hace honor al resto del viaje: la canoa naufraga, se arruinan todas las placas fotográficas, y las colecciones etnográficas deben ser abandonadas. Las últimas jornadas, incluyendo una larga caminata de días, son agónicas, hambrientas, desesperadas. Sin embargo, como nota de justicia poética al inalterable optimismo de Schmidt, las colecciones abandonadas en la selva, consideradas perdidas para siempre, 
llegarían increíblemente a Berlín tres años más tarde, rescatadas y transportadas hasta Cuiabá por sus amigos bacairís.

Postrado por la malaria, Schmidt pudo redimir la derrota xinguana poco tiempo después, al pasar tres semanas entre los guatós del alto Paraguay -los míticos habitantes de los pantanales mencionados en las crónicas de Alvar Núñez Cabeza de Vaca y Félix de Azara. En 1901 los guatós eran pocos y su cultura mostraba ya el impacto del contacto con la sociedad brasileña, al punto que Schmidt reporta cierta "indolencia espiritual” en ellos. De todos modos pudo reunir notas de campo, vocabularios y numerosos objetos para las colecciones del museo, que posteriormente analizaría en detalle en sus estudios sobre los procesos de aculturación de los guatós (SCHMIDT, 1942a, 1942b). Volvería a encontrarlos diez años más tarde, cuando aprovechó el viaje al Congreso Internacional de Americanistas de Buenos Aires para regresar al Mato Grosso (SCHMIDT, 1914a). Decidido a obtener el máximo rédito de este viaje, se internó -con la sola compañía de un mulato- en el territorio de una parcialidad paresí (un grupo de arawaks meridionales autodenominados "kozarinis") que vivía todavía en relativa independencia, entre los cuales logró recopilar abundantes datos y tomar numerosas fotografías (SCHMIDT, 1914b, 1943).

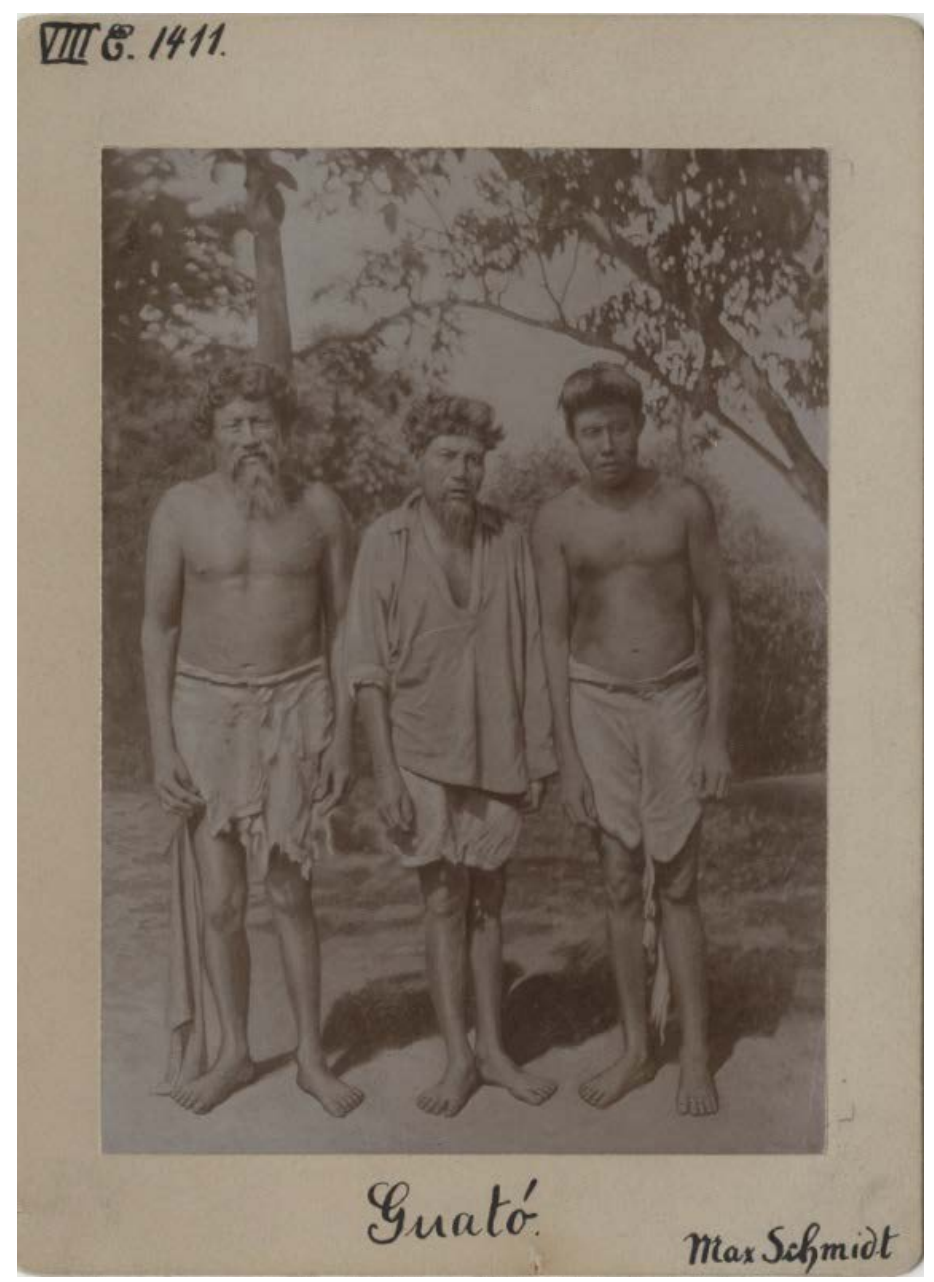

Fig. 1 Guatós (Max Schmidt, 1901. EMB, VIII E 1411)

(Fuente: Ethnologisches Museum der Staatlichen Museen zu Berlin) 
Esta última experiencia de campo con un grupo arawak parece haberlo impresionado, pues al volver a Alemania dedicó su tesis doctoral a un estudio general sobre esa familia lingüística: "Desde un punto de vista geográfico, se trataba de la última terra incognita. Aquí, en este remoto rincón de la Tierra, lejos de cualquier cultura europea, tuve la chance inédita al vivir con los indios de experimentar parte de la expansión de la cultura paresí (una cultura arawak) hacia las poblaciones circundantes" (SCHMIDT, 1917: 7-8). Las observaciones de 1910 sobre ese grupo -las técnicas de agricultura y de conservación de excedentes alimenticios, la incorporación de cautivos de las parcialidades vecinas, la división en clases sociales dominantes y dependientes y su legitimación en términos mitológicos o ceremoniales-podían reinterpretarse ahora a la luz de una perspectiva comparativa mucho más amplia (SCHMIDT, 1917).

La tesis de Schmidt, de hecho, probó estar adelantada a su tiempo en varios sentidos. En primer lugar, porque rastreaba una densa trama de préstamos, conexiones y transformaciones entre los arawaks y diversas culturas amazónicas, pedemontanas y andinas, lo cual justificaba considerarlos una "alta cultura" según las categorizaciones evolutivas de la época. En segundo lugar, porque la experiencia en el terreno le permitió a Schmidt contextualizar de forma admirable su conocimiento museográfico de la cultura material amerindia, anticipando buena parte de los modernos hallazgos arqueológicos, etnohistóricos y antropológicos sobre esa familia lingüística (cf. SUSNIK, 1994; HECKENBERGER, 2002; HECKENBERGER; NEVES, 2009; HORNBORG; HILL, 2012). En tercer lugar, y fundamentalmente, por su misma lógica interpretativa. Para Schmidt la expansión de los pueblos arawaks no podía explicarse por presuntas migraciones masivas, a la manera de los viejos teóricos difusionistas, ni tampoco por factores ecológicos, a la manera de la posterior ecología cultural norteamericana. La mejor forma de entenderla era apelando a una "economía política etnológica” todavía en ciernes (SCHMIDT, 1920, 1921, 1926: 27-28). Según esa clave interpretativa, la notable difusión de los arawaks se debió a la política expansiva de sus "clases dominantes", las cuales sea por medios pacíficos (alianzas matrimoniales, exogamia) o violentos (guerra, rapto de mujeres, robo de niños) perseguían recurrentemente tres metas: la ocupación de la tierra, la captación de la mano de obra, y la obtención de sus medios de producción. Más que una expansión arawak, entonces, se trataba de una auténtica "colonización" caracterizada por los procesos de mestizaje y formación de identidades híbridas, por la diplomacia y por la oposición a la guerra endógena, por el sedentarismo, por una agricultura intensiva con capacidad para generar excedentes, y particularmente por una estructura social jerárquica, compuesta por una clase dependiente y otra dominante, así como también por una ideología bien determinada codificada en torno del rango hereditario, el parentesco genealógico y la legitimación simbólica de la descendencia. En cada caso las eventuales diferencias culturales, lingüísticas y étnicas entre los diversos grupos arawaks se debían entonces a procesos diferentes de simbiosis entre esas élites y sus poblaciones dependientes. 


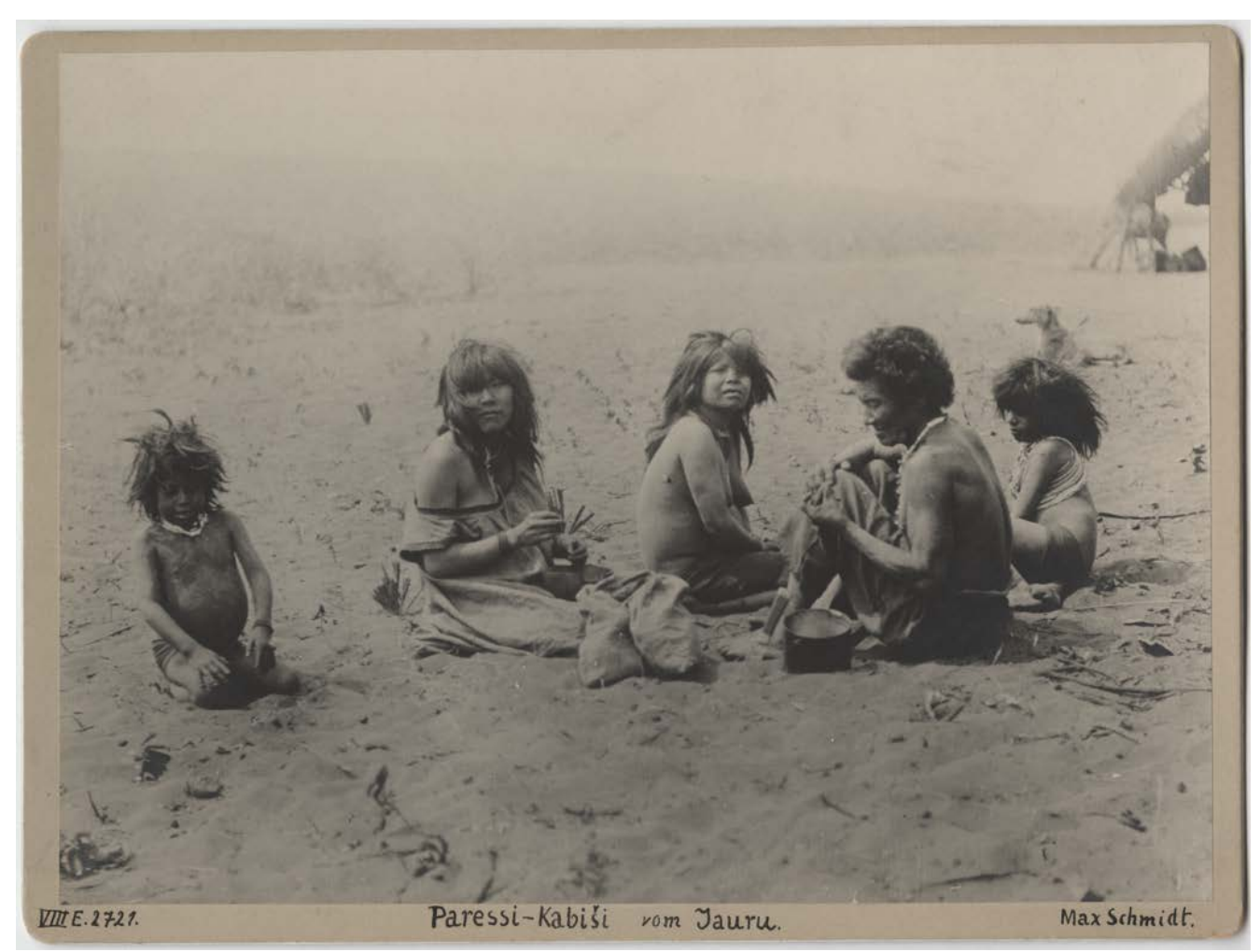

Fig. 2 Mujeres y niños paresi-kabishi de Uazirimi (Max Schmidt, 1910. EMB, VIII E 2721) (Fuente: Ethnologisches Museum der Staatlichen Museen zu Berlin)

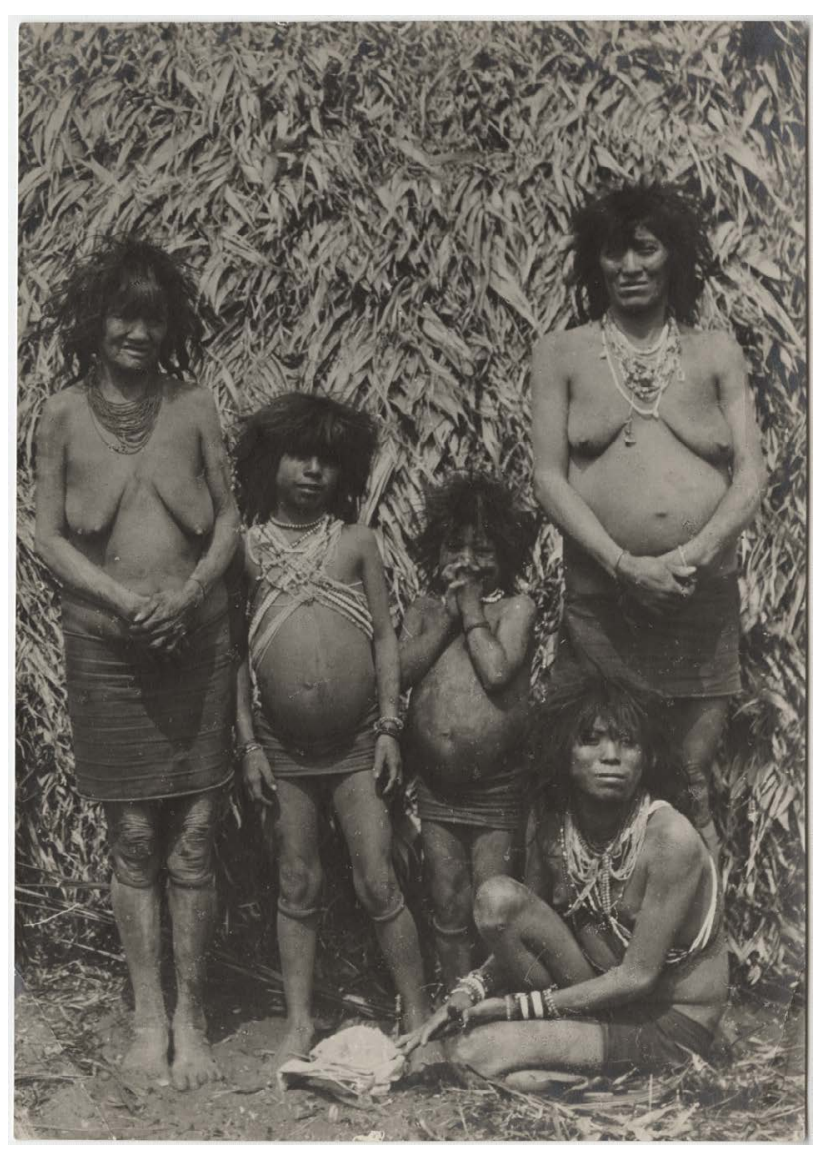

Fig. 3 Mujeres paresi-kabishi en Uazirimi (Max Schmidt, 1910. EMB, VIII E 2715) (Fuente: Ethnologisches Museum der Staatlichen Museen zu Berlin) 
Luego de defender exitosamente la tesis, Schmidt fue nombrado profesor de Etnología en la Universidad de Berlín y, un año después, director de la sección latinoamericana del Museo de Etnología. Hasta 1926 siguió dedicándose a investigaciones de corte más teórico y comparativo, interesándose particularmente por problemas de cultura material. Sin embargo, la nostalgia de la selva lo condujo el año siguiente a emprender un último gran viaje al Mato Grosso.

El viaje resultó tan accidentado como el primero. Comenzó visitando a los viejos amigos bacairís de Cuiabá y Paranatinga, descubriendo con tristeza que muchos de ellos habían muerto en una epidemia de gripe. El hijo de uno de sus viejos guías de 1900 fue su única compañía durante largos tramos del viaje. Pero, para su gusto, los bacairís ya estaban demasiado "pacificados". Desde 1910, las Comisiones de Líneas Telegráficas y el Servicio de Protección de Indios, inspiradas por el activo explorador del Mato Grosso, el general Cândido Mariano da Silva Rondon, sembraban la selva de estaciones telegráficas y "puestos" destinados a atraer y "civilizar" a los indígenas. Por otro lado, los caucheros avanzaban en diversas regiones, y muchas veces provocaban sangrientos conflictos con los indígenas. Con una carta de recomendación de Rondon, Schmidt descendió entonces el río Paranatinga con la intención de estudiar a los kaiabis de filiación tupí. Si los bacairís parecían demasiado aculturados, las noticias que militares, exploradores y caucheros aportaban sobre los kaiabis referían en cambio un cuadro de belicosidad y salvajismo que sin duda debió atraerlo. Pese a contar con escasas provisiones, perder una canoa y recaer en frecuentes ataques de fiebre, logró llegar al puesto Pedro Dantas, en pleno territorio indígena, y estudiar durante un tiempo a los kaiabis que llegaban allí en busca de alimentos, medicinas y herramientas de metal, antes de verse obligado a volver a Cuiabá aquejado otra vez por la malaria (SCHMIDT, 1942c).

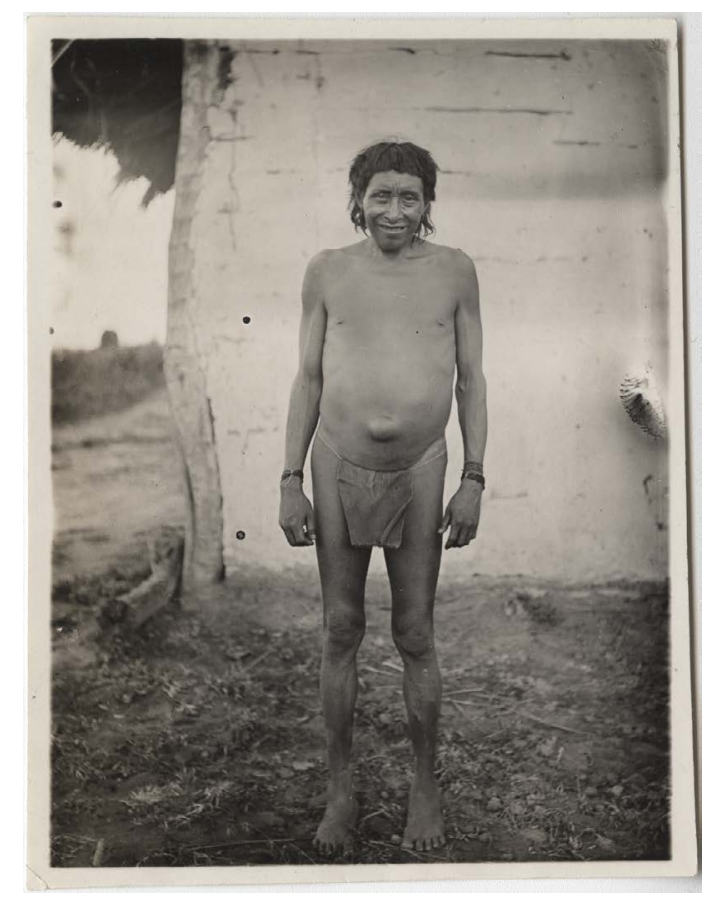

Fig. 4 Iranche de Utiariti (Max Schmidt, 1928. EMB, VIII E 4909)

(Fuente: Ethnologisches Museum der Staatlichen Museen zu Berlin) 
Una vez repuesto, ya en 1928, visitó a los paresís del río Utiariti, muchos de los cuales habían sido concentrados en puestos e incluso trabajaban en el tendido de líneas telegráficas. A pesar de conseguir recopilar mucha información, también entonces se topó con la desagradable noticia de las muertes por epidemias (SCHMIDT, 1943: 10). Allí conoció también a unos iranches que visitaban la estación telegráfica, pero sus breves entrevistas con ellos no fueron muy productivas (SCHMIDT, 1942d). Resolvió entonces regresar hacia el sur, hasta una aldea umotina situada cerca del puesto Humaitá, sobre el alto Paraguay. Pese a que era plena temporada de lluvias, la estadía resultó más fructífera: compartió durante quince días la vida con los indígenas, observó de cerca las interacciones cotidianas, recogió objetos, vocabularios en "lengua primordial" y por las tardes deleitó a sus anfitriones tocando el ya maltrecho violín, mientras éstos se dejaban fotografiar sin problemas. Envalentonado decidió entonces ir en busca de otra parcialidad cercana: tras una confusa escaramuza entre los umotinas "civilizados" y los "salvajes", que casi incluyó un intercambio de flechazos, Schmidt debió apelar a todo su arsenal diplomático -incluyendo, por supuesto, el despliegue de las fotografías de sus viajes anteriores y algunas melodías en el violín- para ser recibido en la aldea de Masepo, donde pudo finalmente presenciar durante varios días la vida cotidiana, tomar fotografías y reunir mediante pacientes trueques una apreciable colección de objetos. Allí trabó amistad con el jefe Kaimanepa, un anciano un tanto irritable pero muy respetado por haber enfrentado valientemente, en varias ocasiones, a los caucheros que invadían su territorio. No sorprende, entonces, que sus nuevos amigos umotinas rechazaran la invitación de acompañarlo a Cuiabá, puesto que no querían "ver las caras de los blancos" (SCHMIDT, 1941: 9).

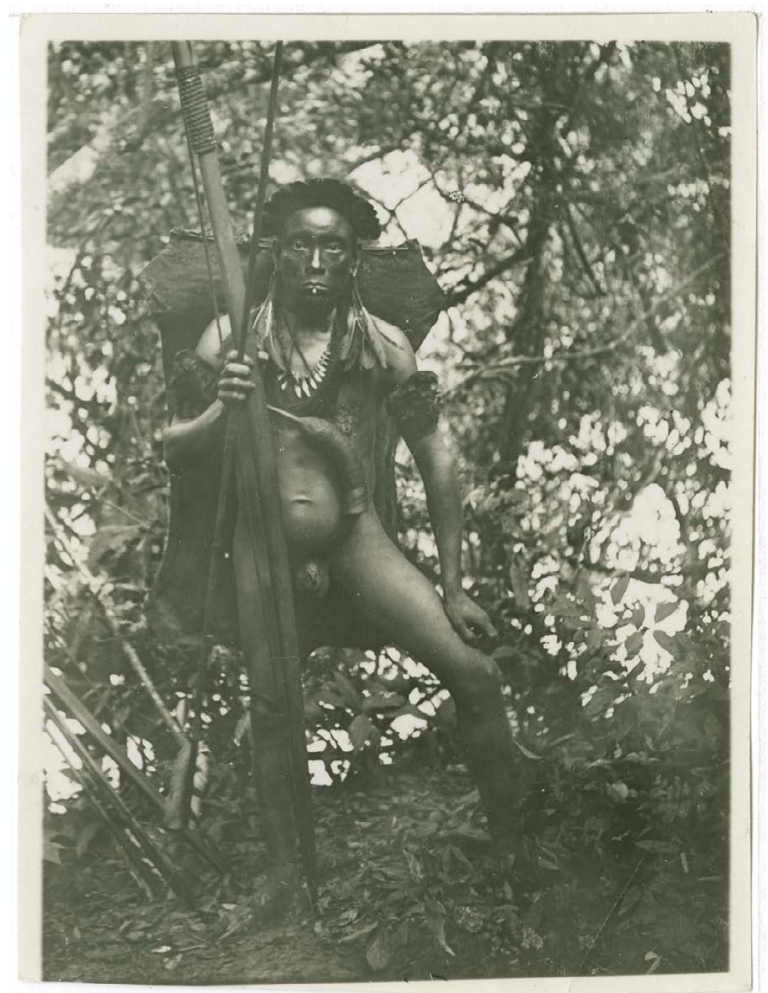

Fig. 5 Umotina del Alto Paraguay (Max Schmidt, 1928. EMB, VIII E 4937)

(Fuente: Ethnologisches Museum der Staatlichen Museen zu Berlin) 
Finalmente, durante el camino de regreso hacia Corumbá, se demoró unos días para estudiar las pinturas rupestres del Morro do Triumpho. Guiada por un viejo baqueano, un "cazador de tigres" de 73 años, la modesta compañía formada por tres hombres y los perros de caza remontó en canoa el pantanoso delta del alto Paraguay. El calor, la fiebre, el agotamiento, las pirañas y nubes de mosquitos impiadosos no consiguieron opacar el entusiasmo de Schmidt por los grabados rupestres que hoy adornan su lápida en el cementerio de Asunción, en Paraguay, y a los cuales calificó como "lo más interesante que yo había visto en todos mis viajes" (SCHMIDT, 1940: 69). Con el regreso a Alemania, en 1928, se cerró su última expedición científica para el Museo de Berlín.

\section{Etnografía y fotografías}

Cuando se repasa la experiencia mato-grossense de Max Schmidt, una de las primeras cosas que llama la atención es su singular empeño por fotografiar la vida indígena aun en las circunstancias menos favorables. En las expediciones pioneras de finales del siglo XIX la fotografía etnográfica era algo difícil, frecuentemente limitada a objetos de la cultura material, tipos físicos y escenas de viaje. Los tempranos empeños de Schmidt deben ser valorados en este contexto. Obtener las imágenes no era sencillo: por un lado, el delicado aparejo fotográfico sin dudas representaba una pesada carga en el modesto cargamento de sus expediciones; por el otro, si bien los indígenas apreciaban las fotos y los retratos impresos en los libros, no se mostraban entusiastas a la hora de posar frente a la cámara, y a veces eran necesarios largos parlamentos diplomáticos antes de obtener la primera imagen: "Conseguí convencer a uno de los caciques de Maimaieti del carácter inofensivo de mi aparato fotográfico. Le pedí que mirara en el espejo de la cámara, y me coloqué delante de la lente. Al comprobar que no ser reflejado así no me provocaba ningún daño, siguió mi ejemplo y así pude fotografiar a todo el grupo" (SCHMIDT, 1942b: 55). Por otro lado, los procedimientos técnicos sumaban dificultades a los de por sí numerosos apremios del viaje; así, el revelado de las fotografías implicaba noches extenuantes bajo una frazada de lana, con la lámpara roja y los instrumentos fotográficos, dejando las piernas a merced de los implacables mosquitos.

Si bien percibía el potencial artístico de esta técnica, es evidente que Schmidt valoraba la fotografía como carta de presentación y ante todo como forma de registro científico. Por un lado, entonces, el empeño por fotografiar obedecía a una razón práctica: la experiencia con los grabados de Steinen (realizados por su primo Wilhelm) le había enseñado que las imágenes -de ellos mismos o de sus vecinos- eran enormemente valoradas por los indígenas xinguanos, y hacían mucho más sencillo el primer contacto. Por otra parte, la fotografía constituía un fin científico en sí mismo. Schmidt descreía de los análisis antropométricos, que jamás practicó. Lejos de los retratos de indígenas posando desnudos, de frente y de perfil, sus fotografías procuraban registrar poses y situaciones cotidianas. De hecho, lo que podríamos llamar su ética profesional revela la perdurable herencia de Bastian y Steinen: Schmidt se mantuvo casi siempre -y en esto reside 
la fuerza y la debilidad de su obra- como un empirista acérrimo, que se contenta con ofrecer informaciones etnográficas fieles. Su percepción de la vida indígena acusa el peso de ese legado, que con frecuencia asume un punto de vista valorativo en el cual podría hasta rastrearse un cierto exotismo romántico muy extendido en la segunda mitad del siglo XIX: la exaltación de una vida indígena percibida como espontánea, fiel a los instintos, libre de las imposturas y las alienaciones de la vida burguesa -en suma, una existencia "natural”. Así, sus páginas más líricas revelan una cierta idealización de la vida en la selva. Sin dudas algo de esto hubo en las razones que lo llevaron a buscar la compañía de los indígenas, e indudablemente el interés de su círculo académico por los Naturvölker representaba alguna variedad de exotismo decimonónico.

Sin embargo, no sería justo reducir la percepción de Schmidt de la vida indígena -la cual llegó a conocer de cerca- a una simple variación de las ideas rousseaunianas, forjadas para consumo europeo. Lejos de cualquier percepción estática o arcaica de la mentalidad indígena, destacaba a menudo la invencible curiosidad de los habitantes del Mato Grosso, su insistencia por aprender palabras en alemán, su insondable necesidad de escuchar la canción Margarethe ejecutada en su violín. Transmitía así una imagen dinámica del contacto entre el solitario científico y sus huéspedes, en la cual la curiosidad etnológica no se restringía de ningún modo al primero y el asombro del "descubrimiento" era siempre recíproco. Las notas de Schmidt, de hecho, suelen reconocer en los indígenas actores auténticamente racionales. Así, por ejemplo, una breve anécdota de campo refleja tanto la noción de una unidad psicológica de la humanidad como, por sobre todo, su respeto particularista por la filosofía social indígena:

\footnotetext{
“Durante mi estadía entre los indios guatós, una mujer (en una imitación inconsciente de la

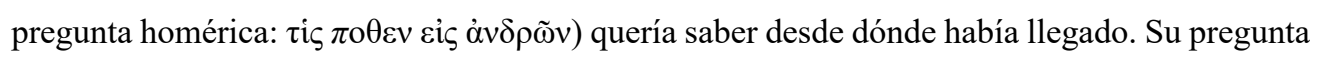
fue: Diruadé iókaguahe nitoavi? (‘¿cómo son las cosas en tu tierra?’). Luego preguntó: ‘¿Hay mucha gente en tu tierra? ¿Hay muchas casas allí?’. Su pregunta sobre la duración de mi viaje fue: ‘¿Estaba grande el río cuando viniste? ¿Estaba tu camino libre de maleza?’. Incluso esas pocas palabras nos permiten dar un vistazo a la vida de estos guatós, y revelan cuán profundamente el río participa de sus pensamientos" (Schmidt 1926: 41).
}

Muy diferente de otras por entonces en boga, esta concepción humanista era herencia de la tradición etnológica alemana condensada en la figura de Bastian, para quien la cultura indígena era una manifestación del espíritu universal tan válida e instructiva como la europea. Schmidt compartía esta posición general, que lo mantuvo siempre a salvo de los vicios evolucionistas o difusionistas, aunque en su caso no implicara repetir sus supuestos y conclusiones idealistas: sus estudios eran siempre localizados, basados en el empirismo más estricto, sin hacer del Mato Grosso un laboratorio cultural o psicológico para esgrimir inferencias generales sobre la humanidad. En los relatos de sus expediciones, pues, se percibe una cierta tensión entre el ideal de los Naturvölker como objeto primordial de la etnología y las realidades mucho más híbridas y complejas que 
encontraba en el terreno. Una buena muestra es su interés por los fenómenos de cambio cultural provocados por el contacto entre indígenas y colonos -por ejemplo, en su análisis sobre la aculturación de los guatós (SCHMIDT, 1942b: 264), o bien sobre el contraste entre los bacairís del Paranatinga (“europeizados") y sus parientes del río Coliseu ("montaraces") (SCHMIDT, 1947). Es que, antes que nada, sus escritos etnográficos son una exhibición de empirismo y respeto por la singularidad del caso ofreciendo una densidad de detalle por momentos abrumadora: los nombres de los bueyes, cada uno de los animales salvajes avistados o cazados, la composición de las sucesivas compañías, la composición del paisaje, los tipos de nudos empleados, cada uno de los platos degustados, el inventario de las transacciones, los bienes entregados, obtenidos o perdidos. De este modo el relato hace explícito, de modo casi exuberante, el escenario preciso en el cual se obtuvo cada dato; y así, muy lejos de una descripción depurada, estática y sedimentada de la vida social indígena, no escatima nunca la contextualización de la misma en un lugar y un momento precisos.

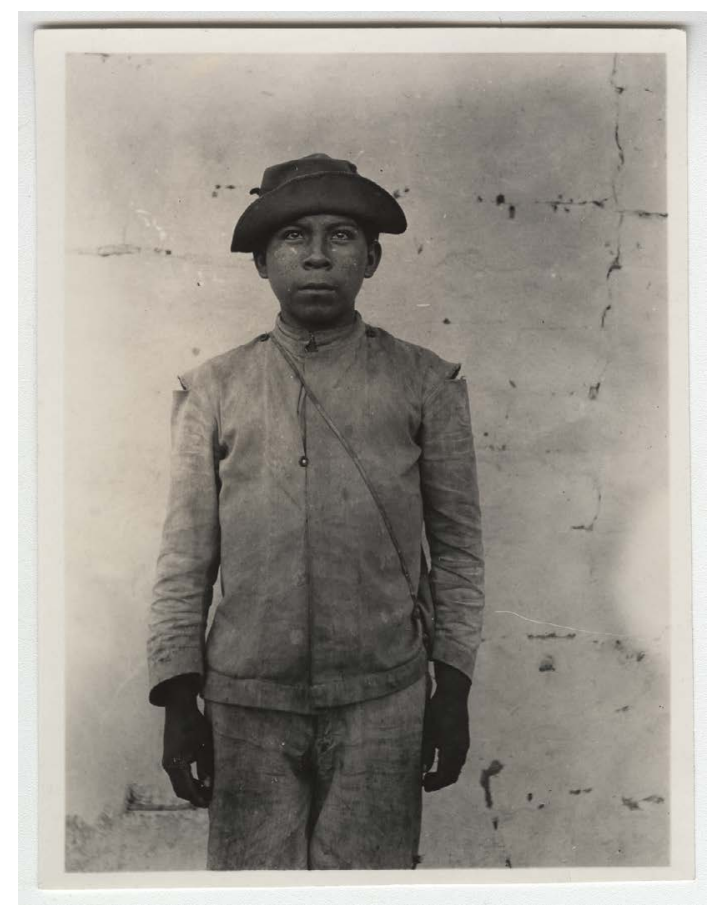

Fig. 6 Muchacho paresi en Utiariti (Max Schmidt, 1928. EMB, VIII E 4920)

(Fuente: Ethnologisches Museum der Staatlichen Museen zu Berlin)

En sus estudios de la organización social indígena, este empirismo de Schmidt se traducía en un marcado individualismo descriptivo. En el caso de los bacairís, por ejemplo, unos pasajes que recuerdan las mejores páginas de Malinowski nos muestran a un jefe y a su hijastro compitiendo impiadosamente por el poder político. Muy lejos de los intereses difusionistas que diseccionaban la cultura o la concebían como una taxa museológica, y mucho más lejos todavía de las especulaciones raciales o evolucionistas, procura siempre ofrecer una semblanza íntima y minuciosa de los intereses y las motivaciones psicológicas de los indígenas en tanto actores individuales. Así, no son pocas las características de la etnografía de Max Schmidt que lo presentan como un

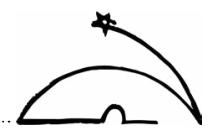


precursor del tipo de etnógrafo científico que sólo iría a imponerse décadas más tarde: su empeño por viajar sin compañeros europeos, la observación rigurosa, el vínculo genuino que procuraba establecer con los indígenas, y ante todo sus intenciones - nunca concretadas- de asentarse un largo tiempo en un solo grupo para realizar un estudio intensivo. Estas intenciones no eran simplemente el efecto de la planificación en Berlín o de la organización práctica de sus expediciones -una peculiar combinación de modestia personal, misantropía y limitados recursos financieros-, sino que respondían a una concepción filosófica del tipo de conocimiento que buscaba lograr.

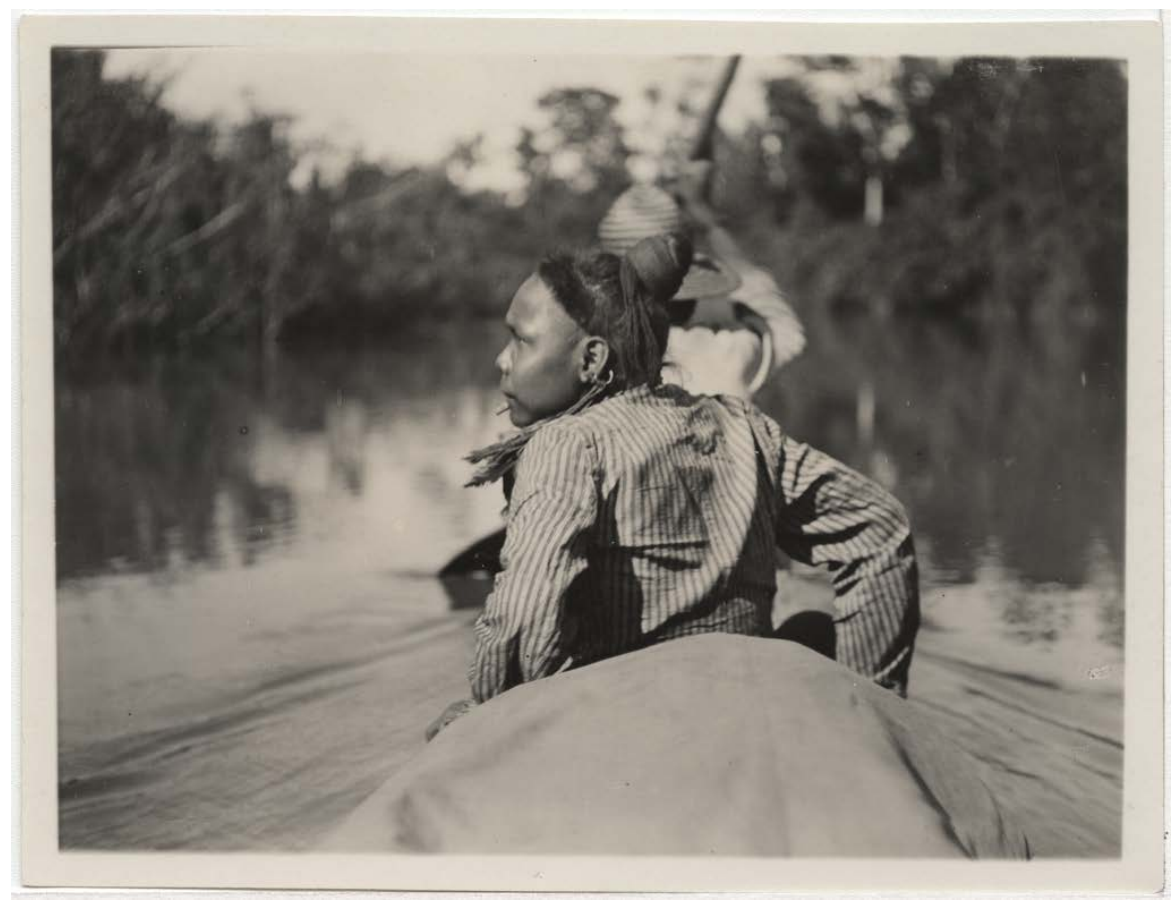

Fig. 7 El umotina Kodonepa en canoa (Max Schmidt, 1928. EMB, VIII E 4934) (Fuente: Ethnologisches Museum der Staatlichen Museen zu Berlin)

En 1929, al regresar de su última expedición, Schmidt daría un giro drástico a su vida: se jubiló, renunció a sus cargos académicos en Alemania y regresó al Brasil con la intención -luego frustrada- de establecerse en las cercanías de Cuiabá, en pleno Mato Grosso. Ya no regresaría nunca a Alemania. No conocemos exactamente los motivos de esta decisión, ni tampoco poseemos muchos datos acerca de este período de su vida. Pero no es difícil entrever aquí sus viejos y persistentes ideales científicos y personales (BALDUS, 1951: 254; SUSNIK, 1991: 9), la utopía personal alimentada por las lecciones de Bastian y Steinen y, ante todo, por los mejores recuerdos de sus primeros viajes:

“Así estaba meditando en la noche, en la playa, delante de una vasta sabana de agua con las montañas como fondo. Pensaba que mi deseo más ardiente era vivir algunos meses en ese pequeño y bonito rincón de la tierra, entre esa gente simple y satisfecha (...) Un viento frío llegó de la superficie de las aguas sumergidas en la niebla. Una sensación extraña se apoderó de mí. 
La viola y el canto en la selva llegaban desde lejos hasta mis oídos. Los indios se preparaban nuevamente para un cururú [baile], recordándome que no debía, por esperanzas perdidas, desdeñar lo que me ofrecía el presente. De manera que fui hasta allá y bailé un alegre vals con la pequeña María" (SCHMIDT, 1942b: 123).

\section{Referencias bibliográficas}

BALDUS, Herbert. Max Schmidt 1874-1950. Revista do Museu Paulista (n.s.), n. 5, p. 253-260, 1951.

BOSSERT, Federico; VILLAR, Diego. Hijos de la selva: la etnografia de Max Schmidt, Santa Monica CA: Perceval Press, 2013.

BUNZ, Matti. Franz Boas and the Humboldtian Tradition: From Volksgeist and Nationalcharakter to an Anthropological Concept of Culture. In: STOCKING, G. W. (ed.). Volksgeist as Method and Ethic. Essays on Boasian Ethnography and the German Anthropological Tradition. Madison - Londres: University of Wisconsin Press, 1996. p. 17-78.

GINGRICH, Andre. The German-Speaking countries. In: BARTH, F.; GINGRICH, A.; PARKIN, R.; SILVERMAN, S. One Discipline, Four Ways: British, German, French, and American Anthropology. Chicago: University of Chicago Press, 2005. p. 59-153.

HECKENBERGER, Michael. Rethinking the arawakan diaspora: hierarchy, regionality and the amazonian formative. In: HILL, Jonathan; SANTOS-GRANERO, Fernando (eds.). Comparative arawakan histories. Rethinking languages family and cultural area in Amazonia. Urbana: University of Illinois Press, 2002. p. 99-122.

HECKENBERGER, Michael; NEVES, Eduardo Góes. Amazonian Archaeology. Annual Review of Anthropology, v. 38 , p. $251-266,2009$.

HORNBORG, Alf; HILL, Jonathan (eds.). Ethnicity in Ancient Amazonia: Reconstructing Past Identities from Archaeology, Linguistics, and Ethnohistory. Boulder: University of Colorado Press, 2011.

KRAUS, Michael. Philological Embedments - Ethnological Research in South America in the Ambience of Adolf Bastian. In: FISHER, M. et al. (eds.). Adolf Bastian and His Universal Archive of Humanity. The Origins of German Anthropology. Hildesheim - Zurich - Nueva York: Georg Olms Verlag, p. 2007. 140-153. 
PENNY, H. Glenn. Objects of culture. Ethnology and Ethnographic Museums in Imperial Germany. Chapel Hill Londres: The University of North Carolina Press, 2002.

SCHADEN, Egon. Pioneiros Alemães da Exploração Etnológica do Alto Xingu. In: PENTEADO COELHO, V. (ed.). Karl von den Steinen: Um Século de Antropologia no Xingu, Universidade de São Paulo: San Pablo, 1993. p. 109-130.

SCHMIDT, Max. Los Bakairí. Revista do Museu Paulista, vol. 1, p. 11-58, 1947.

. Los Paressís. Revista de la Sociedad Cientifica del Paraguay vol. 6, n. 1, p. 1-67, 1943.

. Resultados de mi tercera expedición a los guatós efectuada en el año 1928. Revista de la Sociedad Cientifica del Paraguay, vol. 5, n. 6, p. 41-75, 1942a.

. Estudos de Etnologia Brasileira. Peripécias de uma viagem entre 1900 e 1901. Seus resultados etnológicos. San Pablo: Companhia Editora Nacional, 1942b.

. Los Kayabís en Matto-Grosso (Brasil). Revista de la Sociedad Cientifica del Paraguay, vol. 5, n. 6, p. $1-39,1942 c$.

Los Iranches. Revista de la Sociedad Cientifica del Paraguay, vol. 5, n. 6, p. 35-40, 1942 d.

. Los Barbados o Umotinas en Matto Grosso (Brasil). Revista de la Sociedad Científica del Paraguay, vol. 5 , n. 4, p. 1-42, 1941.

. Nuevos hallazgos de grabados rupestres en Matto-Grosso. Revista de la Sociedad Cientifica del Paraguay, vol. 5, n. 1, p. 63-71, 1940

The Primitive Races of Mankind. A Study in Ethnology. Londres: George Harrap, 1926.

. Grundriss der ethnologischen Volkswirtschaftslehre. Der soziale Wirtschaftsprozess der Menschheit. Sttutgart: Verlag von Ferdinand Enke, 1921.

. Grundriss der ethnologischen Volkswirtschaftslehre. Die soziale Organisation der menschlichen Wirtschaft. Sttutgart: Verlag von Ferdinand Enke, 1920.

. Die Aruaken. Ein Beitrag zum Problem de Kulturverbrietung. Leipzig: Veit \& Co, 1917. 
. Die Guató und ihr Gebiet. Ethnologische und archäologische Ergebnisse der Expedition zum Caracará-Fluss in Matto Grosso. Baessler-Archiv, vol. 4, n. 6, p. 251-283, 1914a.

. Die Paressí-Kabischi. Ethnologische Ergebnisse einer Expedition zu den Quellen des Jaurú und Juruena im Jahre 1910. Baessler-Archiv, vol. 4, n. 4-5, p. 167-250, 1914 b.

SUSNIK, Branislava. Interpretación etnocultural de la complejidad sudamericana antigua: Formación y dispersión étnica. Asunción: Museo Etnográfico Andrés Barbero, 1994.

Prof. Dr. Max Schmidt. Su contribución etnológica y su personalidad. Asunción: Museo Etnográfico Andrés Barbero, 1991.

THIEME, Inge. Karl von den Steinen: Vida e Obra. In: PENTEADO COELHO, Vera (ed.). Karl von den Steinen: Um Século de Antropologia no Xingu. San Pablo: Universidade de São Paulo, 1993. p. 35-108. 